\title{
HUBUNGAN LOKASI FISTULA ARTERIOVENA DAN RIWAYAT PENGGUNAAN KATETER DOUBLE LUMEN IPSILATERAL TERHADAP KEJADIAN HIPERTENSI VENA PERIFER DI RSUP SANGLAH DENPASAR
}

\author{
Aslesa Wangpathi Pagehgiri ${ }^{1}$, Ketut Putu Yasa ${ }^{2}$, Gde Raka Widiana ${ }^{3}$ \\ ${ }^{1}$ Residen Bedah Umum, Fakultas Kedokteran Universitas Udayana, Rumah Sakit Umum Pusat Sanglah, \\ Denpasar, Bali, Indonesia. Korespondensi: aslesa_wp@yahoo.com. \\ ${ }^{2}$ Divisi Bedah Thoraks Kardiovaskular, Fakultas Kedokteran Universitas Udayana, Rumah Sakit Umum Pusat \\ Sanglah, Denpasar, Bali, Indonesia. \\ ${ }^{3}$ Divisi Ilmu Penyakit Dalam, Subdivisi Ginjal Hipertensi, Fakultas Kedokteran Universitas Udayana, Rumah \\ Sakit Umum Pusat Sanglah, Denpasar, Bali, Indonesia.
}

\begin{abstract}
ABSTRAK
Tujuan: untuk mengetahui faktor-faktor yang berhubungan dengan kejadian hipertensi vena perifer paska pembuatan akses fistula arteriovena untuk hemodialysis. Metode: penelitian ini menggunakan rancangan cross sectional. Subyek penelitian adalah pasien dengan Chronic Kidney Disease (CKD) Stadium V dengan akses fistula arteriovena yang menjalani hemodialisis di RSUP Sanglah selama periode Desember 2016-Desember 2017 sebanyak 141 sampel. Hasil: dilakukan uji multivariat dengan analisa regresi logistik untuk masing-masing faktor, dengan mengendalikan faktor perancu, yaitu usia, jenis kelamin, etiologi CKD, lama hemodialisis, dan status gizi pasien. Nilai rasio prevalens untuk lokasi fistula arteriovena brakiosefalika sebesar 15,2 dengan nilai $\mathrm{p}<0,001$. Nilai rasio prevalens untuk riwayat pemakaian kateter double lumen ipsilateral sebesar 20,9 dengan nilai $\mathrm{p}<0,001$. Simpulan: dari hasil analisis data secara statistika dapat disimpulkan lokasi fistula arteriovena brakiosefalika dan riwayat penggunaan kateter double lumen secara statistika bermakna terhadap kejadian hipertensi vena perifer pada pasien CKD stage $\mathrm{V}$ yang menjalani hemodialisis regular di RSUP Sanglah Periode Desember 2016-Desember 2017.
\end{abstract}

Kata kunci: hipertensi vena perifer, fistula arteriovena, kateter double lumen, akses hemodialisis.

\section{THE CORRELATION BETWEEN LOCATION OF ARTERIOVENOUS FISTULA FOR DIALYSIS AND HISTORY OF IPSILATERAL DOUBLE LUMEN CATHETER INSERTION WITH PERIPHERAL VEIN HYPERTENSION AT RSUP SANGLAH DENPASAR}

\author{
Aslesa Wangpathi Pagehgiri ${ }^{1}$, Ketut Putu Yasa ${ }^{2}$, Gde Raka Widiana ${ }^{3}$ \\ ${ }^{1}$ General Surgery Residents, Faculty of Medicine, University of Udayana, Sanglah General Hospital, Denpasar, \\ Bali, Indonesia. Correspondence: aslesa_wp@yahoo.com. \\ ${ }^{2}$ Thorax Cardiovascular Surgery Division, Faculty of Medicine, University of Udayana, Sanglah General \\ Hospital, Denpasar, Bali, Indonesia. \\ ${ }^{3}$ Internal Medicine Division, Nephrology Subdivision, Faculty of Medicine, University of Udayana, Sanglah \\ General Hospital, Denpasar, Bali, Indonesia.
}

\begin{abstract}
Aim: to ascertain the factors that correlated with the incidence of peripheral vein hypertension after arteriovenous fistula creation for dialysis. Methods: this is a cross-sectional study. The subject in this study are patients with chronic kidney disease (CKD) stage V undergone hemodialysis at
\end{abstract}


RSUP Sanglah in December 2016 until December 2017. The total participants in this study are 141 people. Results: multivariate test with logistic regression analysis was done in every risk factor with controlling the compounding factors, that is age, sex, etiology of CKD, duration of dialysis, and nutritional status. The prevalence ratio for brachiocephalic location for dialysis is 15.2 with $\mathrm{p}$ value $<0.001$. The prevalence ratio for history of ipsilateral double lumen catheter for dialysis insertion is 20.9 with $p$ value $<0.001$. Conclusion: from the analysis of data study with statistic, concludes that brachiocephalic location of AV fistula, and history of ipsilateral double lumen catheter insertion are statistically significant to have a correlation with the incidence of peripheral vein hypertension after fistula creation.

Keywords: peripheral vein hypertension, arteriovenous fistula, double lumen catheter, hemodialysis access.

\section{PENDAHULUAN}

Hipertensi vena perifer setelah pembuatan fistula arteri-vena atau fistula arteriovena terjadi pada sekitar $10-15 \%$ pasien yang menjalani hemodialisis dengan akses fistula arteriovena. Etiologi yang paling umum adalah stenosis dan atau trombosis pada sistem vena sentral sekunder setelah pemasangan kateter sebelumnya dan berkembang menjadi hipertensi vena perifer setelah pembuatan fistula arteriovenal. ${ }^{1}$

Stenosis vena sentralis dapat menyebabkan hipertensi vena perifer yang menimbulkan berbagai keluhan pada pasien dan menimbulkan rusaknya akses fistula arteriovena yang penting untuk hemodialisis pasien. Etiologi stenosis vena sentralis yang berhubungan dengan hemodialisis paling sering diinisiasi dengan pemasangan kateter hemodialisis. Bila akses ditempatkan ipsilateral pada oklusi subklavia dapat menyebabkan peningkatan tekanan vena. Secara anatomis, hipertensi vena dapat terjadi dalam semua bentuk akses ekstremitas atas karena arterialisasi dari vena. Bagaimanapun, dengan semakin proximal akses, lebih tinggi alirannya sehingga gejala semakin menjadi lebih kuat. ${ }^{2}$

\section{METODE}

Penelitian ini menggunakan rancangan cross sectional untuk mengetahui faktorfaktor yang berhubungan dengan kejadian komplikasi hipertensi vena perifer paska pembuatan akses fistula arteriovena untuk hemodialisis. Subyek penelitian adalah pasien dengan Chronic Kidney Disease (CKD) stadium $\mathrm{V}$ dengan akses fistula arteriovena yang menjalani hemodialisis di RSUP Sanglah. Penelitian ini dilakukan selama 1 tahun dari bulan Desember 2016 hingga Desember 2017 dengan jumlah sampel 141 pasien.

Analisis data pada penelitian dilakukan dalam 3 tahap, yaitu analisis univariabel, bivariabel dan multivariabel. Analisis univariabel bertujuan untuk menggambarkan karakteristik subyek dan variabel penelitian. Analisis bivariabel bertujuan untuk mengetahui peningkatan kejadian hipertensi vena perifer memiliki hubungan dengan lokasi fistula arteriovena dan riwayat penggunaan kateter double lumen hemodialisis ipsilateral dengan menghitung nilai prevalence ratio (PR). Analisis multivariabel bertujuan untuk mengetahui pengaruh murni satu variabel bebas terhadap 1 variabel tergantung dengan mengontrol (mengendalikan) variabel bebas lainnya yang juga 
mempengaruhi variabel tergantung dengan menggunakan uji regresi logistik.

\section{HASIL}

Karakteristik peserta penelitian digambarkan pada Tabel 1, dibagi berdasarkan umur, jenis kelamin, etiologi CKD, lama hemodialisis, dan status gizi pasien. Karakteristik usia didapatkan nilai rerata usia peserta penelitian adalah 53,1 tahun dengan standar deviasi 11,9 tahun. Berdasarkan jenis kelamin, didapatkan laki-laki sebanyak 84 responden $(59,6 \%)$ dan jenis kelamin perempuan sehonrol 57 responden $(40,4 \%)$. Etiologi

pada peserta penelitian dibagi

kelompok, kelompok pertan etiologi bukan diabetes

(pielonefritis kronis, glom $\epsilon$ kronis, sindroma nefrotik, Syst,

Erythematosus, ginjal polik pasien dengan etiologi Diabt

Disease (DKD). Karakteristik adalah lama pasien menjalani hemodialisis, yaitu sejak pertama kali menjalani hemodialisis, walaupun belum memiliki akses hemodialisis fistula arteriovena. Karakteristik terakhir yang diperhitungkan adalah status gizi pasien, dengan menggunakan body mass index (BMI) dengan satuan $\mathrm{kg} / \mathrm{m}^{2}$.

Dari hasil penelitian yang ditampilkan pada Tabel 2, dengan dilakukan analisis bivariat untuk mencari hubungan lokasi fistula arteriovena dan riwayat penggunaan kateter double lumen ipsilateral terhadap kejadian hipertensi vena perifer. Pada penelitian yang dilakukan oleh penulis didapatkan pasien dengan lokasi fistula arteriovena brakiosefalika yang menjalani hemodialisis di RSUP Sanglah Denpasar pada Desember 2016 hingga Desember 2017 yang mengalami kejadian hipertensi vena perifer sebanyak 15 responden
$(31,7 \%)$ dan didapatkan rasio prevalens untuk lokasi fistula arteriovena brakiosefalika terhadap kejadian hipertensi vena perifer sebesar 15,2 sehingga pasien dengan fistula arteriovena brakiosefalika memiliki risiko 15,2 kali lebih tinggi mengalami hipertensi vena perifer, dengan nilai $\mathrm{p}$ dibawah 0,001 sehingga signifikan secara statistika.

Tabel 1. Karakteristik Subyek Penelitian berdasarkan Umur, Jenis Kelamin, Etiologi CKD, Lama Hemodialisis, dan Status Gizi Pasien.

\begin{tabular}{ll}
\hline Variabel & $\mathbf{n}=\mathbf{1 4 1}$ \\
\hline $\begin{array}{l}\text { Umur (tahun) rerata } \pm \text { SD } \\
\text { Jenis Kelamin }\end{array}$ & $53,1 \pm 11,9$ \\
$\quad$ Laki-Laki & $84(59,6 \%)$ \\
$\quad \begin{array}{l}\text { Perempuan } \\
\text { Etiologi CKD }\end{array}$ & $57(40,4 \%)$ \\
$\quad$ Bukan DM & $109(77,3 \%)$ \\
$\quad$ DM & $32(22,7 \%)$ \\
Lama Hemodialisis $\quad$ (tahun) & $4,7 \pm 2,8$ \\
$\quad$ rerata \pm SD & \\
Status Gizi (BMI) rerata \pm SD & $21,8 \pm 3,2$ \\
\hline $\begin{array}{l}\text { SD: standar deviasi; DM: diabetes melitus; CKD: } \\
\text { chronic kidney disease; BMI: body mass index. }\end{array}$
\end{tabular}

Tabel 2. Analisis Bivariat Hubungan Lokasi Fistula Arteriovena dan Riwayat Penggunaan Kateter Double Lumen Ipsilateral terhadap Kejadian Hipertensi Vena Perifer.

\begin{tabular}{|c|c|c|c|c|c|}
\hline \multirow[t]{2}{*}{ Variabel } & \multicolumn{2}{|c|}{$\begin{array}{c}\text { Hipertensi Vena } \\
\text { Perifer }\end{array}$} & \multirow[t]{2}{*}{ PR } & \multirow[t]{2}{*}{$\begin{array}{l}95 \% \\
\text { CI }\end{array}$} & \multirow[t]{2}{*}{ Nilai $\mathbf{p}$} \\
\hline & Ya & Tidak & & & \\
\hline \multicolumn{6}{|l|}{ Lokasi } \\
\hline $\mathrm{BC}$ & $\begin{array}{c}15 \\
(31.7 \%)\end{array}$ & $\begin{array}{c}28 \\
(68.3 \%)\end{array}$ & \multirow[b]{2}{*}{15,0} & 3,994 & \multirow[b]{2}{*}{$<0,001$} \\
\hline $\mathrm{RC}$ & $\begin{array}{c}3 \\
(3,0 \%)\end{array}$ & $\begin{array}{c}97 \\
(97.0 \%)\end{array}$ & & $\begin{array}{c}- \\
56,417\end{array}$ & \\
\hline \multicolumn{6}{|c|}{ Riwayat CDL Ipsilateral } \\
\hline $\mathrm{Ya}$ & $\begin{array}{c}11 \\
(37,9 \%)\end{array}$ & $\begin{array}{c}18 \\
(62,1 \%)\end{array}$ & \multirow{2}{*}{13,1} & 4,063 & \multirow{2}{*}{$<0,001$} \\
\hline Tidak & $\begin{array}{c}5 \\
(4,5 \%)\end{array}$ & $\begin{array}{c}107 \\
(95,5 \%)\end{array}$ & & $\begin{array}{c}- \\
42,099\end{array}$ & \\
\hline
\end{tabular}

CI: confidence interval; $\mathrm{BC}$ : brachiocephalica; $\mathrm{RC}$ : radiocephalica; $\mathrm{PR}$ : prevalence ratio; $\mathrm{CDL}$ : catheter double lumen. 
Pada penelitian ini didapatkan pasien dengan riwayat penggunaan kateter double lumen ipsilateral yang mengalami kejadian hipertensi vena perifer sebanyak 11 responden $(37,9 \%)$ dibandingkan pasien dengan hipertensi vena perifer yang tidak memiliki riwayat penggunaan kateter double lumen ipsilateral sebanyak 18 pasien $(62,1 \%)$, pasien yang tidak memiliki riwayat penggunaan kateter double lumen ipsilateral sebanyak 5 peserta penelitian $(4,5 \%)$, dan yang tidak mengalami hipertensi vena perifer sebanyak 108 (95,5\%), didapatkan rasio prevalens untuk riwayat penggunaan kateter double lumen ipsilateral terhadap kejadian hipertensi vena perifer sebesar 20,9 sehingga pasien dengan riwayat penggunaan kateter double lumen ipsilateral memiliki risiko 20,9 kali lebih tinggi mengalami hipertensi vena perifer, dengan nilai $\mathrm{p}$ dibawah 0,001 sehingga signifikan secara statistika. Hal ini serupa dengan penelitian-penelitian yang sudah dilakukan sebelumnya.

Tabel 3. Hasil analisis regresi logistik hubungan lokasi fistula arteriovena terhadap kejadian hipertensi vena perifer pada pasien dengan CKD Stadium $\mathrm{V}$ dengan akses fistula arteriovena yang menjalani hemodialisis di RSUP Sanglah setelah dikontrol dengan variabel umur, jenis kelamin, etiologi CKD, lama hemodialisis, dan status gizi peserta penelitian.

\begin{tabular}{|c|c|c|c|}
\hline $\begin{array}{l}\text { Variabel } \\
\text { Kategori } \\
\end{array}$ & $\begin{array}{l}\text { Adjusted } \\
\text { OR }\end{array}$ & $95 \% \mathrm{CI}$ & Nilai $p$ \\
\hline $\begin{array}{r}\text { Lokasi fistula AV } \\
\text { brakiosefalika }\end{array}$ & 15,2 & $\begin{array}{l}3,861- \\
59,660\end{array}$ & $<0,001$ \\
\hline Usia & 1,0 & $\begin{array}{c}0,918- \\
1,044\end{array}$ & 0,5 \\
\hline $\begin{array}{l}\text { Jenis kelamin } \\
\text { perempuan }\end{array}$ & 2,2 & $\begin{array}{c}0,619- \\
7,864\end{array}$ & 0,2 \\
\hline Etiologi DM & 2,5 & $\begin{array}{l}0,700- \\
9,235\end{array}$ & 0,2 \\
\hline BMI & 1,0 & $\begin{array}{c}0,767- \\
1,147\end{array}$ & 0,5 \\
\hline $\begin{array}{l}\text { Lama } \\
\text { hemodialisis }\end{array}$ & 0,9 & $\begin{array}{c}0,715- \\
1,090\end{array}$ & 0,2 \\
\hline
\end{tabular}

Tabel 4. Hasil analisis regresi logistik hubungan riwayat penggunaan kateter double lumen ipsilateral terhadap kejadian hipertensi vena perifer pada pasien dengan CKD Stadium V dengan akses fistula arteriovena yang menjalani hemodialisis di RSUP Sanglah setelah dikontrol dengan variabel umur, jenis kelamin, etiologi CKD, lama hemodialisis, dan status gizi peserta penelitian.

\begin{tabular}{|c|c|c|c|}
\hline $\begin{array}{l}\text { Variabel } \\
\text { Kategori }\end{array}$ & $\begin{array}{l}\text { Adjusted } \\
\text { OR }\end{array}$ & $95 \% \mathrm{CI}$ & Nilai p \\
\hline $\begin{array}{c}\text { Riwayat CDL } \\
\text { ipsilateral }\end{array}$ & 20,9 & $\begin{array}{l}5,014- \\
87,229\end{array}$ & $<0,001$ \\
\hline Usia & 1,0 & $\begin{array}{c}0,934- \\
1,056\end{array}$ & 0,8 \\
\hline $\begin{array}{r}\text { Jenis Kelamin } \\
\text { Perempuan }\end{array}$ & 1,9 & $\begin{array}{c}0,535- \\
6,909\end{array}$ & 0,3 \\
\hline Etiologi DM & 2,3 & $\begin{array}{c}0,604- \\
9,003\end{array}$ & 0,2 \\
\hline BMI & 0,9 & $\begin{array}{c}0,746- \\
1,098\end{array}$ & 0,3 \\
\hline $\begin{array}{l}\text { Lama } \\
\text { hemodialisis }\end{array}$ & 0,8 & $\begin{array}{c}0,607- \\
0,979\end{array}$ & 0,3 \\
\hline
\end{tabular}

Selanjutnya dilakukan analisis multivariabel dengan menggunakan uji regresi logistik, dengan cara memasukkan variabel bebas yaitu lokasi fistula AV brakiosefalika pada Tabel 3 dan variabel bebas riwayat penggunaan kateter double lumen ipsilateral pada Tabel 4. Dari Tabel 3 didapatkan hasil analisis regresi logistik hubungan lokasi fistula arteriovena brakiosefalika terhadap kejadian hipertensi vena perifer pada pasien dengan CKD Stadium V dengan akses fistula arteriovena yang menjalani hemodialisis di RSUP Sanglah setelah dikontrol dengan variabel umur, jenis kelamin, etiologi CKD, lama hemodialisis, dan status gizi peserta penelitian dengan adjusted OR sebesar 15,2. Hal ini menunjukkan pasien dengan lokasi fistula arteriovena brakiosefalika memiliki kemungkinan 15,2 kali lebih besar mengalami kejadian hipertensi vena perifer dibandingkan 
pasien dengan lokasi fistula arteriovena brakiosefalika untuk akses hemodialisis dibawah 1 tahun, dengan nilai $\mathrm{p}<0,001$ menunjukkan bahwa lokasi fistula arteriovena brakiosefalika signifikan secara statistika sebagai faktor yang mempengaruhi kejadian hipertensi vena perifer.

Dari Tabel 4 didapatkan hasil analisis regresi logistik hubungan riwayat penggunaan kateter double lumen ipsilateral terhadap kejadian hipertensi vena perifer pada pasien CKD Stadium V dengan akses fistula arteriovena yang menjalani hemodialisis di RSUP Sanglah setelah dikontrol dengan variabel umur, jenis kelamin, etiologi CKD, lama hemodialisis, dan status gizi peserta penelitian dengan adjusted OR sebesar 20,9. Hal ini menunjukkan pasien dengan riwayat penggunaan kateter double lumen ipsilateral memiliki kemungkinan 20,9 kali lebih besar mengalami kejadian hipertensi vena perifer dibandingkan pasien tanpa riwayat penggunaan kateter double lumen ipsilateral untuk akses hemodialisis. Didapatkan nilai $\mathrm{p}<0,001$ menunjukkan bahwa riwayat penggunaan kateter double lumen ipsilateral signifikan secara statistik sebagai faktor yang mempengaruhi kejadian hipertensi vena perifer.

\section{DISKUSI}

Gejala klinis dimulai dengan edema pada satu jari atau lebih, dan ibu jari sering terkena. Edema dapat meluas ke seluruh tangan dan lengan bawah. Tahap yang lebih berat ditandai oleh perubahan warna kebiruan pada jari-jari, perubahan menjadi sianotik, dan pigmentasi pada kasus yang berat, nekrosis kulit, perubahan gangren jari dan neuralgia mungkin terjadi. Akhirnya ulserasi pada kulit tampak serupa seperti yang terlihat pada hipertensi vena kronis pada betis. Diagnosis ditegakkan menggunakan venografi ekstremitas atas. Puncture langsung pada akses arteriovena termasuk juga pencitraan pada akses, dengan perhatian lebih pada anastomosis vena, dan sirkulasi vena sentral untuk mendeteksi oklusi vena sentral atau arterialisasi pada vena. ${ }^{1-3}$

Derajat keparahan (grade) hipertensi vena dibagi dari 0 hingga 3 , seperti berikut tingkat 0 tidak ada gejala, tingkat 1 terdapat gejala ringan, gejala minimal, diskolorisasi, pembengkakan ekstremitas minimal, tingkat 2 dengan keluhan tingkat sedang, perasaan tidak nyaman yang intermiten, dan pembengkakan yang parah, dan tingkat 3 dengan gelaja berat, yaitu perasaan yang tidak nyaman dan pembengkakan yang konstan, hiperpigmentasi, bahkan hingga ulserasi vena. $^{2-3}$

Insidensi pasti mengenai kejadian hipertensi vena perifer pada populasi pasien dengan dialisis tidak diketahui dengan pasti. Diperkirakan antara 5\% hingga $20 \%$ pasien dengan hemodialisis mengalami kejadian stenosis vena sentral. Stenosis vena sentral paska pemakaian kateter double lumen subklavia diperkirakan terjadi pada $42 \%$ hingga $50 \%$ pasien hemodialisis, dan $10 \%$ mengalami kejadian stenosis vena sentral paska pemasangan kateter double lumen jugularis interna. $^{3}$ Hal ini serupa dengan hasil penelitian yang dilakukan oleh penulis, dimana didapatkan kejadian hipertensi vena perifer pada pasien yang menjalani dialisis dengan fistula arteriovena sebesar $11,3 \%$ dari seluruh pasien yang menjalani hemodialisis di RSUP Sanglah Denpasar pada Desember 2016 hingga Desember 2017.

Penelitian yang dilakukan oleh Barrett et al. dan Teruya et al. pada tahun 2003 
didapatkan terjadinya gejala pembengkakan lengan, nyeri, dan gejala lain pada pasien dengan hipertensi vena perifer yang menjalani hemodialisis paska penggunaan akses dialisis ipsilateral ataupun pemakaian pacemaker bervariasi dari 2 minggu hingga 38 bulan, dengan rata-rata timbulnya gejala adalah 12,5 bulan. $^{4}$

Akses brakiosefalika dan brakialbasilika adalah pilihan akses yang tradisional atau umum digunakan pada akses lengan atas autogen dan berhubungan dengan tingkat patensi yang lebih baik dibandingkan akses arteriovena autogen lengan bawah. Pada penelitian yang dilakukan oleh Dorobanţu et al (2013) kejadian hipertensi vena perifer lebih tinggi pada pasien dengan akses brakiosefalika. $^{3,5}$ Pada penelitian yang dilakukan oleh penulis didapatkan pasien dengan lokasi fistula arteriovena brakiosefalika yang menjalani hemodialisis di RSUP Sanglah Denpasar pada Desember 2016 hingga Desember 2017 yang mengalami kejadian hipertensi vena perifer sebanyak 15 responden $(31,7 \%)$ dan didapatkan rasio prevalens untuk lokasi fistula arteriovena brakiosefalika terhadap kejadian hipertensi vena perifer sebesar 15,2 sehingga pasien dengan fistula arteriovena brakiosefalika memiliki risiko 15,2 kali lebih tinggi mengalami hipertensi vena perifer, dengan nilai $\mathrm{p}$ dibawah 0,001 sehingga signifikan secara statistik.

Penelitian dengan angiografi pada pasien yang simptomatik menunjukkan prevalensi tinggi untuk stenosis vena sentral dengan pemakaian kateter subklavia, dengan berkembangnya stenosis vena subklavia pada sekitar $25-50 \%$ pasien pada berbagai macam studi. $^{6}$ Pada penelitian yang dilakukan oleh penulis didapatkan pasien dengan riwayat penggunaan kateter double lumen ipsilateral yang mengalami kejadian hipertensi vena perifer sebanyak 11 responden $(37,9 \%)$ dibandingkan pasien dengan hipertensi vena perifer yang tidak memiliki riwayat penggunaan kateter double lumen ipsilateral sebanyak 18 pasien $(62,1 \%)$, pasien yang tidak memiliki riwayat penggunaan kateter double lumen ipsilateral sebanyak 5 peserta penelitian $(4,5 \%)$, dan yang tidak mengalami hipertensi vena perifer sebanyak 108 (95,5\%), didapatkan rasio prevalens untuk riwayat penggunaan kateter double lumen ipsilateral terhadap kejadian hipertensi vena perifer sebesar 20,9 sehingga pasien dengan riwayat penggunaan kateter double lumen ipsilateral memiliki risiko 20,9 kali lebih tinggi mengalami hipertensi vena perifer, dengan nilai $\mathrm{p}$ dibawah 0,001 sehingga signifikan secara statistik. Hal ini serupa dengan penelitian-penelitian yang sudah dilakukan sebelumnya.

Hipertensi vena perifer yang sebagian besar disebabkan oleh stenosis vena sentral berhubungan dengan alat intravaskular atau pemakaian kateter pada kebanyakan kasus, walaupun kadang bisa juga idiopatik. Kejadian hipertensi vena perifer pada pasien dengan hemodialisis tanpa riwayat pemasangan central venous catheter (CVC) pada sisi ipsilateral dimungkinkan karena peningkatan aliran darah dan cedera pada sisi ipsilateral dari akses tanpa memperdulikan lokasi (subklavia atau jugular interna), jumlah dan durasi pemakaian yang lebih besar untuk penggunaan kateter double lumen meningkatkan risiko untuk stenosis vena sentral. Pada satu penelitian mengenai stenosis vena sentral subklavia, rerata penggunaan kateter subklavia adalah 1,6 
dan rerata durasi pemakaian kateter adalah 5,5 minggu. Penelitian lainnya, studi prospektif pada kateter vena subklavia menunjukkan stenosis lebih sering dan persisten pada pemakaian 6 bulan yaitu pada jumlah pemakaian yang lebih besar dan waktu penggunaan yang lebih lama. Pada satu penelitian didapatkan prevalensi yang lebih tinggi untuk stenosis vena sentral pada penggunaan kateter dialisis subklavia (42\%) dibandingkan dengan kateter dialisis jugular interna $(10 \%){ }^{6}$

Stenosis vena sentral karena pemasangan kateter vena sentral sebagian besar terjadi karena peningkatan inflamasi, peningkatan stres oksidatif, aktivasi leukosit, rilis myeloperoksidase dan aktivasi kaskade koagulasi setelah pemasangan kateter. Cedera endotel dimulai dengan trauma inisial dari kanulasi vena yang diperkuat dengan keberadaan benda asing yang tidak biocompatible. Selanjutnya, pergerakan konstan kateter dengan respirasi, pergerakan kepala, dan perubahan postur, disertai dengan peningkatan aliran dan turbulensi dari akses arteriovena, mengubah cedera, menyebabkan deposisi platelet dan penebalan dinding vena. Aktivasi leukosit menyebabkan rilis myeloperoksidase dan pembentukan agregat platelet, sehingga menyebabkan thrombosis intravaskular. Kateter seringkali dihubungkan dengan pembentukan thrombus, sering berkaitan dengan stenosis vena pada sisi yang sama, walaupun thrombus dan stenosis berhubungan satu sama lain. ${ }^{6}$

Hipertensi vena biasanya merupakan hasil dari stenosis vena sentral atau inkompetensi katup di aliran keluar vena pada akses arteriovena. Stenosis atau oklusi vena subklavia yang signifikan timbul setelah pemasangan alat pada sisi akses dapat bersifat sementara atau permanen. Perangkat ini dapat berupa (1) pacemaker, (2) kawat defibrillator, (3) kateter vena sentral untuk nutrisi parenteral, (4) memonitor tekanan, dan (5) hemodialisis. Pemasangan kateter akses hemodialisis secara perkutan menyebabkan insidensi stenosis vena sentral sebanyak $10 \%$ hingga $40 \%$. Selama kurun waktu mereka menjalani dialisis, sekitar $15 \%$ sampai $20 \%$ dari pasien hemodialisis berkembang menjadi stenosis atau oklusi total pada vena subklavia. Kenyataannya, kejadian sebenarnya lebih banyak karena pada pasien dengan gejala yang tidak tampak (asimtomatik) yang memiliki riwayat penggunaan akses dialisis sementara dapat memiliki stenosis vena subklavia ketika diperiksa secara rutin. Barrett et al. telah melaporkan sekitar 50\% dari pasien dialisis tanpa gejala memiliki stenosis vena subklavia ketika diperiksa secara rutin. Risiko ini diyakinkan meningkat dengan jumlah kateterisasi dan total hari penggunaan kanulasi pada sirkulasi vena sentral. Riwayat penggunaan kateter dialisis sementara diduga menjadi faktor utama dalam peningkatan jumlah masalah ini pada beberapa tahun terakhir. ${ }^{2}$

Identifikasi kejadian hipertensi vena perifer adalah hal yang penting, bahkan ketika belum menimbulkan gejala yang mengganggu pasien, karena dapat menyebabkan peningkatan tekanan pada vena dan meningkatkan risiko kegagalan akses. $^{3}$

Tujuan utama dari diagnosis dan terapi hipertensi vena adalah mengurangi gejala dan untuk menjaga fungsi akses. Bentuk ringan dari komplikasi, sebagian besar ditunjukkan dengan edema, dapat diobati dengan memposisikan ekstremitas dan penggunaan bebat. Ligasi akses dan penempatan di lokasi lain telah digunakan 
sebagai pilahan utama dari terapi, yang menurunkan aliran ke dalam sirkulasi vena dan mengurangi edema lengan dan gejala sisa hipertensi vena. Pilihan lain pengelolaan hipertensi vena yang berat mungkin termasuk angioplasti transluminal berbasis kateter perkutaneus dan revisi stent intravaskular, rekonstruksi sirkulasi vena sentral dengan bypass bagian oklusif ke vena yang paten dengan aliran langsung, dengan tambahan antikoagulan dan antibiotika. ${ }^{3,7,8}$

\section{SIMPULAN}

Pada penelitian ini dapat disimpulkan bahwa terdapat hubungan lokasi fistula arteriovena brakiosefalika dan riwayat penggunaan kateter double lumen ipsilateral terhadap peningkatan kejadian hipertensi vena perifer. Sehingga dapat disarankan oleh penulis bahwa lokasi fistula arteriovena radiosefalika sebagai pilihan utama untuk akses dialisis dibandingkan akses hemodialisis brakiosefalika, penggunaan kateter double lumen pada sisi ipsilateral fistula arteriovena sebaiknya dihindari sebagai akses hemodialisis, dan pasien dengan riwayat kateter double lumen ipsilateral sebaiknya menjalani screening untuk melihat stenosis vena sentralis sebelum dilakukan operasi fistula arteriovena pada sisi ipsilateral.

\section{UCAPAN TERIMA KASIH}

Penulis menyatakan terima kasih kepada pembimbing, guru, keluarga, teman-teman, dan semua pihak yang telah membantu terlaksananya penelitian ini. Penelitian ini didanai secara pribadi oleh peneliti.

\section{PERNYATAAN}

Penulis menyatakan bahwa tidak ada pihak yang memiliki konflik kepentingan dalam penelitian ini.

\section{DAFTAR PUSTAKA}

1. Hall HC, Moudgill N, Kahn M, et al. An unusual cause of venous hypertension after dialysis access creation. Ann Vasc Surg. 2011;25:983.e1-4.

2. Neville RF, Abularrage J, White PW, et al. Venous Hypertension Associated with Arteriovenous Hemodialysis Access. Sem Vasc Surg. 2004;17:50-6.

3. Linda $\mathbf{M H}$, Rivero M. Hemodialysis Access: Nonthrombotic Complications. In: Cronenwett JL, Johnston KW, editors. Rutherford's Vascular Surgery, 8th Edition. Philadelphia: Elsevier; 2014. p.2335-50.

4. Teruya TH, Abou-Zamzam AM Jr, Limm W, et al. Symptomatic Subclavian Vein Stenosis and Occlusion in Hemodialysis Patients with Transvenous Pacemakers. Annals of Vascular Surgery Inc. 2003;17:5269.

5. Dorobanţu LF, Ştiru O, Bulescu C, et al. Complications of Autogenous Arteriovenous Fistulas. In: Suzuki H, editor. Hemodialysis. London: InTech Open Science; 2013. p.621-34.

6. Agarwal AK. Central Vein Stenosis. American Journal of Kidney Disease. 2013;61:1001-15.

7. Kaufman JS, O'Connor TZ, Zhang JH, et al. Randomized Controlled Trial Of Clopidogrel Plus Aspirin To Prevent Hemodialysis Access Graft Thrombosis. $J$ Am Soc Nephrol. 2003;14:2313-21.

8. Sood P, Sinson GP, Cohen EP. Subdural Hematomas In Chronic Dialysis Patients: Significant And Increasing. Clin J Am Soc Nephrol. 2007;2:956-9. 